\title{
Análise da hidrografia da Coxilha Rica, Sul do município de Lages - SC
}

\author{
Cosme Polese* \\ Francisco Henrique de Oliveira** \\ Carla Luciane Lima*** \\ Felipe Echenique Alves ${ }^{* * * *}$
}

\section{Resumo}

A Coxilha Rica integra à porção sul do município de Lages, localizado entre as bacias hidrográficas dos rios Lava Tudo, Pelotas e Pelotinhas. Este trabalho procura explorar o conceito de uma região como a Coxilha Rica, influenciada pelo uso e ocupação do solo, ser fornecedora de água para a bacia hidrográfica a qual pertence. A Coxilha Rica, com seus $1.136,5 \mathrm{Km}^{2}$, conta com 4.663 $\mathrm{km}$ de corpos de água e grande quantidade de nascentes, detendo uma hidrografia relevante e deve ser considerada fornecedora de água de qualidade para a bacia hidrográfica a qual pertence. Essa qualidade encontrada na água presente no território da Coxilha Rica pode ser explicada pelo uso e ocupação do solo, em grande parte explorado pela atividade de pecuária extensiva, com baixa lotação de animais, permitindo dessa forma a manutenção da cobertura vegetal nativa e um baixo impacto aos corpos de água.

** $\quad$ Mestrado Profissional em Planejamento Territorial e Ambiental UDESC - Lages (cosmepolese@yahoo.com.br).

**** Professor Doutor. Mestrado Profissional em Planejamento Territorial e Ambiental - UDESC - Florianópolis (chico.udesc@gmail.com).

****** Eng e $n$ h e i ra F 1 o r e s t a 1 . (carla_engflorestal@yahoo.com.br). Florianópolis. bolsista de iniciação científica - UDESC -

Geosul, Florianópolis, v. 30, n. 59, p 47-66, jan./jun. 2015 
POLESE, C. et al. Análise da hidrografia da Coxilha Rica, Sul do município...

Palavras-chave: Coxilha Rica; Corpos de água; Nascentes; Uso do solo.

Analysis of hydrographic Coxilha Rica, South Municipality of Lages

\begin{abstract}
The Coxilha Rica includes the southern portion of the city of Lages, located between the basins of the rivers Lava Tudo, Pelotas and Pelotinhas. This paper seeks to explore the concept of a region as Coxilha Rica, influenced by the land use and occupation, being the water supplier to the basin which it belongs. The Coxilha Rica , with its $1,136.5 \mathrm{~km}^{2}$, has $4663 \mathrm{~km}$ of water bodies and a large number of springs, holding a relevant hydrographic and must be regarded supplier of quality water to the basin which it belongs. This quality found in the water present in the territory of Coxilha Rica can be explained by the land use and occupation, largely exploited by the activity of extensive livestock rearing, with low stocking of animals, thereby allowing the maintenance of native vegetation and low impact water bodies.
\end{abstract}

Key words: Coxilha Rica; Bodies of water; Springs; Land use.

\title{
Introdução
}

Um dos grandes desafios atuais é a firmação de um compromisso global que assegure o equilíbrio entre $o$ desenvolvimento econômico e social e a proteção ambiental. Nas últimas décadas no Brasil, as interferências humanas sob o meio natural foram intensificadas, contribuindo para a acentuação de diversos problemas ambientais e socioeconômicos.

A Coxilha Rica integra a porção sul do município de Lages, constituindo um amplo território ocupado por campos naturais e remanescentes de matas com Araucárias, contando com um sistema hídrico relevante, com rios de importância local e regional, localizado entre as bacias hidrográficas dos rios Lava Tudo, Pelotas e Pelotinhas (DETZEL, 2010). Lages, município sede, possui 
POLESE, C. et al. Análise da hidrografia da Coxilha Rica, Sul do município...

2.644,3 mil $\mathrm{Km}^{2}$ de área, e por sua vez, é o maior município em extensão territorial do estado catarinense.

O sul do Brasil é considerado por NIMER (1979) como uma das áreas do globo que apresenta a melhor distribuição de chuvas durante $o$ ano. Segundo o autor, os sistemas de circulação atmosférica associados à ocorrência de chuvas atuam de forma mais ou menos semelhante sobre toda a Região Sul. Essa boa distribuição de chuvas, na Coxilha Rica é representada pela grande quantidade de corpos d'água. Influenciando diretamente o regime de chuvas têm-se os tipos climáticos. De acordo com o mapeamento climático do Brasil, produzido pelo IBGE (2002) na escala 1:5.000.000, o Estado de Santa Catarina abrange três diferentes tipos climáticos que variam no sentido leste-oeste: subquente, mesotérmico brando e mesotérmico mediano. Ainda segundo o IBGE (2002), a região da Coxilha Rica é caracterizada pela ocorrência do clima Temperado Mesotérmico Brando, do tipo super úmido, sem estação seca e com temperatura média variando entre $10^{\circ} \mathrm{C}$ e $15^{\circ} \mathrm{C}$.

A empresa RTK Engenharia (2005) ao elaborar o Estudo Ambiental Integrado da Bacia do Rio Pelotinhas, demonstrou na caracterização climatológica para as PCH's dos rios Lava Tudo e Pelotinhas, dados que podem ser extrapolados para toda a área de Coxilha Rica, uma vez que esta inclui grande parte da bacia:

[...] na bacia, especialmente no inverno e início da primavera, há predominância de tempo bom com dias ensolarados, porém interrompidos por sequências de dias chuvosos, decorrentes da frente polar. As linhas de instabilidade tropical ocasionam dias de chuvas intensas e de curta duração, em particular no final da primavera e no verão.

Conforme a compartimentação hidrográfica do Brasil, determinada pela Resolução do Conselho Nacional de Recursos Hídricos $n^{\circ} 32$ de 15/10/2003, a área de estudo está inserida na Região Hidrográfica do Uruguai, que é constituída unicamente pela bacia hidrográfica do rio Uruguai, e situada em território brasileiro, argentino e uruguaio. A área da Coxilha Rica situa-se na Sub-bacia 
POLESE, C. et al. Análise da hidrografia da Coxilha Rica, Sul do município...

do Uruguai Alto, e de acordo com a Lei ${ }^{\circ} 10.949$ de 09/11/1998, que dispõe sobre a caracterização de Santa Catarina em regiões hidrográficas, pertence a Região Hidrográfica 4 - Planalto de Lages e, nesta, integralmente na bacia do rio Pelotas (Figura 1).

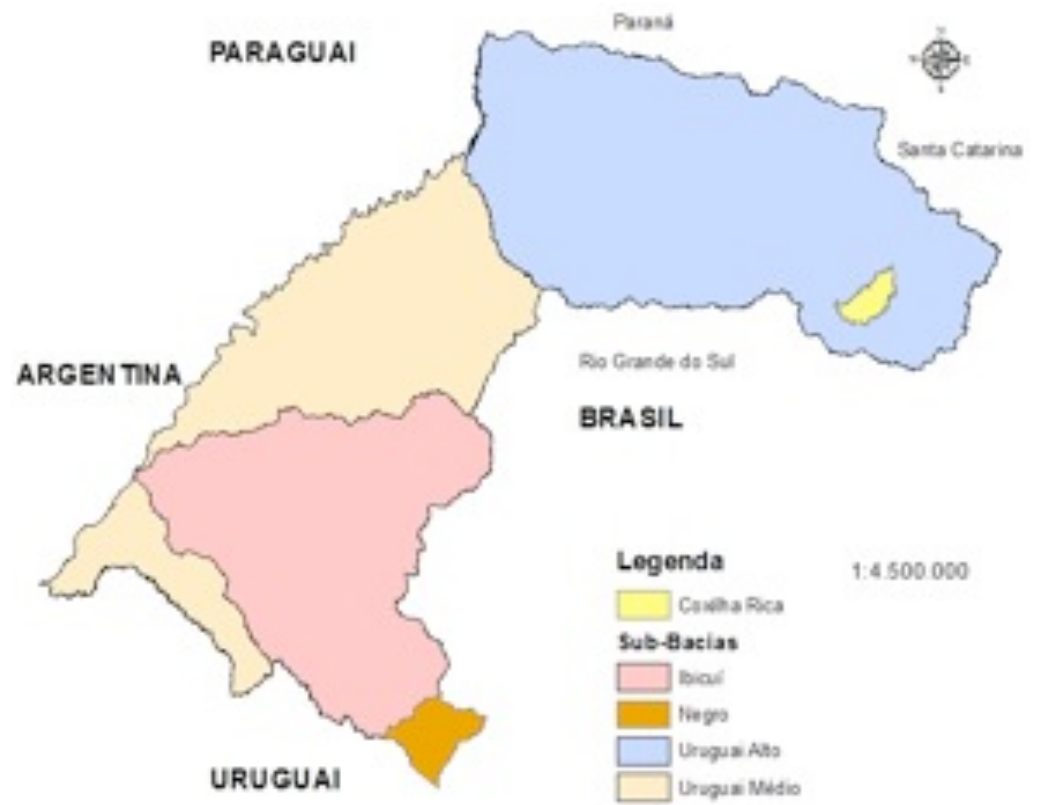

Figura 1: Bacia hidrográfica do Rio Uruguai e suas sub-bacias, com destaque em amarelo para região da Coxilha Rica. Fonte: Adaptado de EPE, 2006.

A área de estudo, foi escolhida por apresentar grande valor ambiental, paisagístico, histórico e cultural. A Coxilha Rica está circundada por rios com potencial de geração de hidroeletricidade, onde mais de uma dezena de empreendimentos encontram-se projetados, o que demonstra a riqueza de recursos hídricos na área.

A preocupação com a proteção dos recursos hídricos da região deve-se à crescente demanda pelo uso da água e a 
POLESE, C. et al. Análise da hidrografia da Coxilha Rica, Sul do município...

diminuição da disponibilidade de água de boa qualidade, sendo de extrema importância o planejamento adequado de sua utilização.

O marco legal da gestão de recursos hídricos no Brasil é chamado de Código de Águas datado de 1934. Somente na década de 80 o país voltou a tratar do assunto legal/institucional da gestão ambiental, fato comprovado pela aprovação da Lei 9.433, que instituiu a Política Nacional de Recursos Hídricos, promulgada em 08 de janeiro de 1997, regulamentando o inciso XIX do art. 21 da Constituição Federal. Através desta lei foram definidos alguns instrumentos básicos para o gerenciamento dos recursos hídricos, como o enquadramento dos corpos de água e, classes, segundo os usos preponderantes da água.

A Lei Federal $n^{\circ}$ 9.433/97 instituiu a Política Nacional de Recursos Hídricos - PNRH. Segundo ela, considera-se a água como um bem de domínio público limitado, dotado de valor econômico, cuja gestão deve sempre proporcionar o seu uso múltiplo (art. $1^{\circ}$, I, II e IV).

Em âmbito estadual o Decreto n. ${ }^{\circ} 14.250$, de 05/06/1981 regulamenta dispositivos da Lei n. ${ }^{\circ}$ 5.793, de 15/10/1980, referentes à proteção e a melhoria da qualidade ambiental. O Decreto, em seu artigo $1^{\circ}$, define meio ambiente como sendo a interação dos fatores físicos, químicos e biológicos que condicionam a existência de seres vivos e de recursos naturais e culturais e estabelece padrões e limites para garantia da proteção do meio ambiente. E em seu artigo $5^{\circ}$ trata da classificação dos corpos de água no estado, sendo considerados de classe 1 os que possuem águas que podem ser destinadas ao abastecimento doméstico sem tratamento prévio ou com simples desinfecção; classe 2 aqueles com águas destinadas ao abastecimento doméstico, após tratamento convencional, à irrigação de hortaliças ou plantas frutíferas e à recreação de contato primário; classe 3 os corpos que apresentam águas destinadas ao abastecimento doméstico, após tratamento convencional, à preservação de peixes em geral e de outros elementos da fauna e da flora e à dessedentação de animais; e classe 4 aqueles com águas destinadas ao abastecimento doméstico, 
POLESE, C. et al. Análise da hidrografia da Coxilha Rica, Sul do município...

após tratamento avançado, ou à navegação, à harmonia paisagística e ao abastecimento industrial, à irrigação e a usos menos exigentes.

A legislação ambiental no Brasil vem estabelecendo regras para a garantia de que todos os indivíduos possam usufruir o direito ao meio ambiente ecologicamente equilibrado, bem de uso comum do povo e essencial à sadia qualidade de vida, conforme presa a Constituição Federal.

O novo Código Florestal Brasileiro, Lei n ${ }^{\circ} 12.651 / 12$, entre outros aspectos, dispõe sobre as áreas de preservação permanente APP. A importância das APP é relacionada com o cumprimento de função ecológica, qual seja a de manutenção dos recursos hídricos, da paisagem, da estabilidade geológica, da biodiversidade, do fluxo gênico de flora e fauna, da proteção do solo e do bem-estar das populações humanas. Nesse aspecto, vale ressaltar que as áreas de preservação permanente ao longo dos cursos de água são vitais para a garantia da proteção das águas, uma vez que formam uma barreira, atuando como filtro dos poluentes transportados pelo deflúvio superficial e contenção da erosão.

Este artigo procura explorar o conceito de uma região como a Coxilha Rica, influenciada pelo uso e ocupação do solo, ser fornecedora de água para a bacia hidrográfica a qual pertence.

\section{Material e método}

A Coxilha Rica possui cerca de $1.136,5 \mathrm{Km}^{2}$ de área, com um perímetro de $249,25 \mathrm{~km}$, correspondendo a aproximadamente $43 \%$ da área do município de Lages (Figura 2), compondo-se em uma extensa planície ondulada de campos naturais com remanescentes de matas de araucária, a cerca de $900 \mathrm{~m}$ acima do nível do mar. 
POLESE, C. et al. Análise da hidrografia da Coxilha Rica, Sul do município...

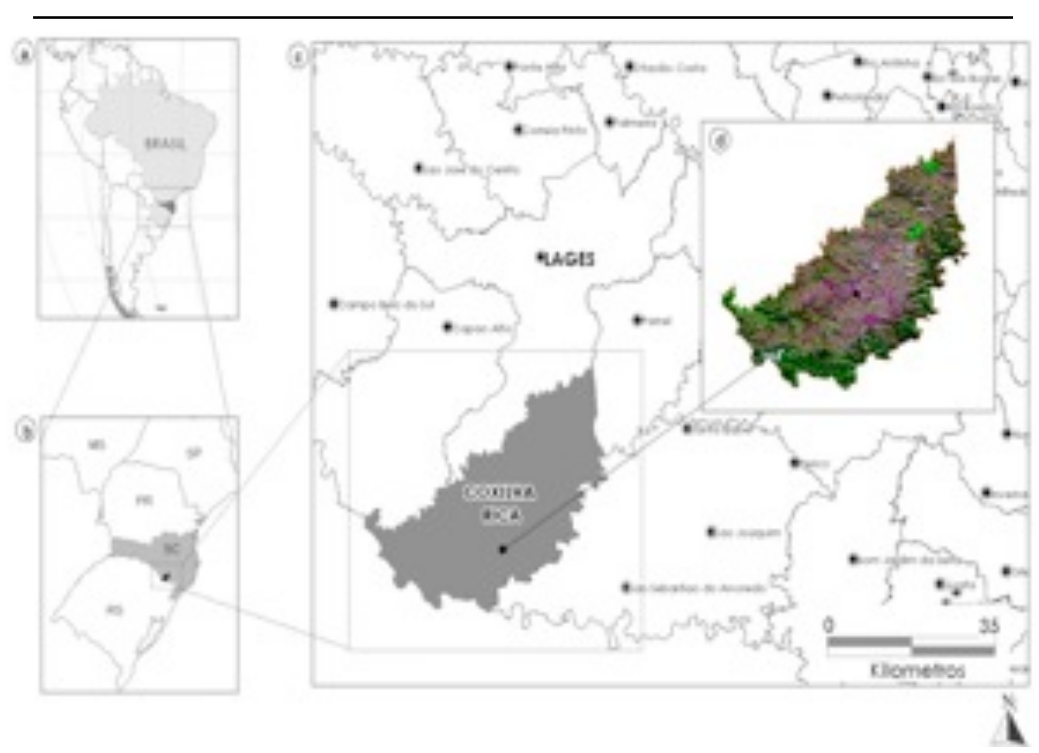

Figura 2: Território da Coxilha Rica (d) e sua inserção no contexto global (a), regional (b) e local (c). Fonte: Detzel, 2010.

A metodologia do trabalho consistiu na utilização da restituição hidrográfica e do sistema hidrográfico ortocodificado feito a partir do levantamento aerofotogramétrico de todo território do Estado, elaborado pela Secretaria de Desenvolvimento Sustentável - SDS de Santa Catarina, em escala de 1:10.000, realizado entre os anos de 2010 e 2012. O material foi disponibilizado pela prefeitura municipal de Lages e o trabalho desenvolvido no Laboratório de Geoprocessamento da FAED UDESC. Para o estabelecimento da área de estudo foi feito o mapeamento da região da Coxilha Rica, na porção sul do território do município de Lages - SC, que compreende a área delimitada pelos Rios Pelotas, Pelotinhas, Lava Tudo e Cipó, e pela fronteira 
POLESE, C. et al. Análise da hidrografia da Coxilha Rica, Sul do município...

seca, divisa entre os municípios de Lages e Painel - SC. Para tanto foi utilizado o software Arc View ${ }^{\circledR}$ 10.1.

A área da Coxilha Rica tem em curso, iniciativas de estudos propostos por órgão públicos, na direção de salvaguardar o território, como o Instituto do Patrimônio Histórico e Artístico Nacional - IPHAN, que trabalha na busca de chancela à paisagem como Paisagem Cultural Brasileira, envolvendo parte leste da Coxilha Rica e o Ministério do Meio Ambiente - MMA, que tramita projeto para criação de uma Unidade de Conservação - UC, denominada "Refugio da Vida Silvestre dos Campos de Cima da Serra", cuja área perpassa a sub-bacia do Rio Pelotas e do Rio Lava Tudo pela margem direita na área da Coxilha Rica. Considerando o exposto e objetivando obter-se uma relação entre número de corpos de água e número de nascentes na área, optou-se por excluir da área de estudo as áreas mencionadas acima, por essas já possuem iniciativas de preservação, restando então uma área alvo.

Com a área alvo demarcada, foram utilizadas diferentes ferramentas do software de geoprocessamento Arc View ${ }^{\circledR} 10.1$ para obtenção dos resultados. A ferramenta "Clip" foi utilizada para delimitação da hidrografia dentro da região estudada na Coxilha Rica. Em seguida, foi utilizada a ferramenta de densidade para obtenção das regiões com maior incidência de corpos de água, que resultou em uma divisão da densidade dos corpos de água em quatro classes, sendo elas: não determinado, onde não foi possível a representação, baixa, média e alta densidade. A partir dai, foram selecionadas aleatoriamente, cinco áreas de amostragem para representação da área alvo. Nas áreas de amostragem foram quantificados os corpos de água e vetorizados manualmente, em pontos, os locais de nascentes que dão origem a um corpo de água, a fim de possibilitar uma melhor análise relacionada à importância da região como fornecedora de água e sua extrema necessidade de preservação frente ao avanço de culturas e práticas agrícolas. 
POLESE, C. et al. Análise da hidrografia da Coxilha Rica, Sul do município...

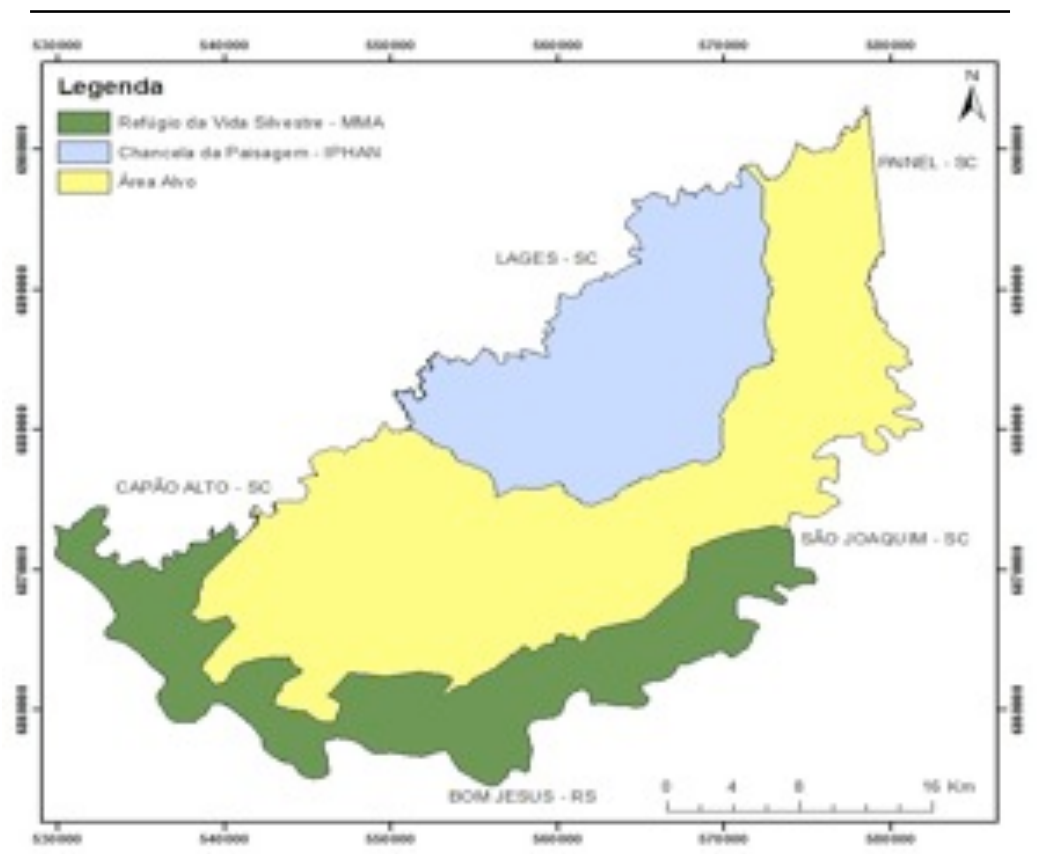

Figura 3: Compartimentação da área de estudo, resultando em uma área alvo (em amarelo).

\section{Resultados e discussão}

Do ponto de vista hidrológico, a área da Coxilha Rica contribui para o incremento da produção hídrica, contemplando três bacias principais: a bacia do rio Pelotinhas, a bacia do rio Lava Tudo, ambas sub-bacias do rio Pelotas e, a bacia do próprio rio Pelotas (Figura 4).

De acordo com a Engevix (2003), com relação a umidade nos solos da região, a precipitação é maior que a Evapotranspiração Potencial (EVP) e a Evapotranspiração Real (EVR) em todos os meses do ano, não havendo portanto na Coxilha Rica déficit de água no solo em nenhum período. 
POLESE, C. et al. Análise da hidrografia da Coxilha Rica, Sul do município...

A hidrografia da Coxilha Rica, em um território com 1.136,5 $\mathrm{Km}^{2}$, conta com um número relevante de corpos de água, somando uma extensão de $4.663 \mathrm{~km}$.

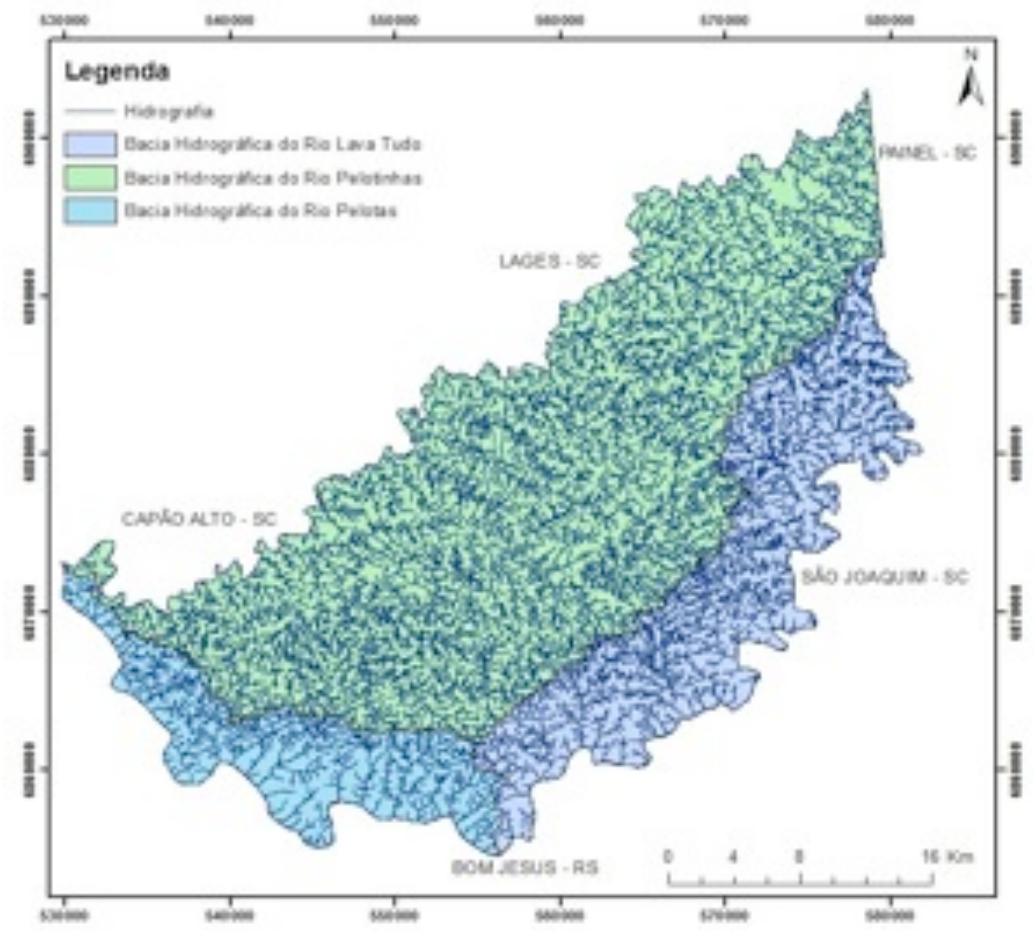

Figura 4: Hidrografia e bacias hidrográficas que compõem a área da Coxilha Rica.

De acordo com Detzel (2010), que elaborou um Diagnóstico Ambiental e Socioeconômico na Coxilha Rica, a bacia do Rio Pelotinhas ocupa uma área correspondente a 64,8 \% da Coxilha Rica, a bacia do Rio Lava Tudo, $22,8 \%$ e a do Rio Pelotas 12,5\%. Porém, de acordo com a restituição hidrográfica feita a partir do levantamento aerofotogramétrico do Estado, tais dados apresentam os seguintes 
POLESE, C. et al. Análise da hidrografia da Coxilha Rica, Sul do município...

valores: Bacia do Rio Pelotinhas: 734,73 $\mathrm{Km}^{2}$ correspondendo a 64,7\%; Bacia do Rio Lava Tudo: 261,44 $\mathrm{Km}^{2}$ correspondendo a 23\% e do Pelotas 140,32 $\mathrm{Km}^{2}$ correspondendo a 12,3\%.

Ainda segundo Detzel (2010), a área da Coxilha Rica conta com $961,4 \mathrm{~km}$ de cursos fluviais, sendo que o curso de água principal do Rio Pelotinhas conta com 104,4 km, o curso de água principal do Rio Lava Tudo com 71,5 km e o do Rio Pelotas 44,8 Km.

Aprimorando-se esses dados, baseado na restituição hidrográfica feita a partir do levantamento aerofotogramétrico do Estado, obtêm-se os seguintes dados: A Coxilha Rica, englobando suas três sub-bacias, conta com $4.663 \mathrm{~km}$ de cursos fluviais, sendo que o Rio Pelotinhas tem 110,2 km de curso fluvial e sua sub-bacia drena $3.125 \mathrm{~km}$ de cursos fluviais considerando a sua margem esquerda, dentro da Coxilha Rica. O Rio Lava Tudo se estende por $73,12 \mathrm{~km}$, drenando $1.074 \mathrm{~km}$ de cursos fluviais na margem direita de seu curso, na Coxilha Rica. O Rio Pelotas por sua vez, estendese por 44,91 km, drenando $464 \mathrm{~km}$ de cursos fluviais, correspondendo a margem direita, na Coxilha Rica.

Em um estudo elaborado pela empresa RTK Consultoria (2005), na bacia do rio Pelotinhas, a ocupação dos solos é esparsa, onde predominam áreas de cultivo e pastagens. De acordo com a análise da qualidade da água do Rio Pelotinhas, dos parâmetros analisados, nenhum apresentou valores que ultrapassaram os limites estabelecidos para o enquadramento dos corpos de água na classe 2, tanto pela legislação ambiental estadual como pela federal.

De acordo com ETS (2005) e Engevix (2003), os resultados das análises da qualidade da água do Rio Lava Tudo mostram uma boa oxigenação e considerando os dados obtidos, o Rio Lava Tudo também é enquadrado nos limites da classificação 2. Ainda, os dados de qualidade da água do Rio Pelotas, obtidos pela empresa Engevix (2003) mostram águas bem oxigenadas, $\mathrm{pH}$ neutro, valores baixos de turbidez e de DBO, considerando-se o Rio Pelotas como possuidor de água de qualidade para consumo humano.

Esses estudos demonstram que além de quantidade, a Coxilha Rica possui água com padrões de qualidade, de acordo 
POLESE, C. et al. Análise da hidrografia da Coxilha Rica, Sul do município...

com a classificação dos corpos de água de Santa Catarina, própria para abastecimento doméstico e demais fins.

Considerando-se apenas a área alvo do estudo, em um território com $584,7 \mathrm{Km}^{2}$, os corpos de água somam uma extensão de $2.531 \mathrm{~km}$. A distribuição desses milhares de corpos de água na área alvo é demonstrada na Figura 5, onde se tem a divisão da densidade dos corpos de água em quatro classes, sendo elas: não determinado, onde não foi possível a representação, baixa, média e alta densidade. Observou-se que a maior parte do território se enquadrou nas classes de média e alta densidade, comprovando a grande quantidade de corpos de água presentes na área alvo.

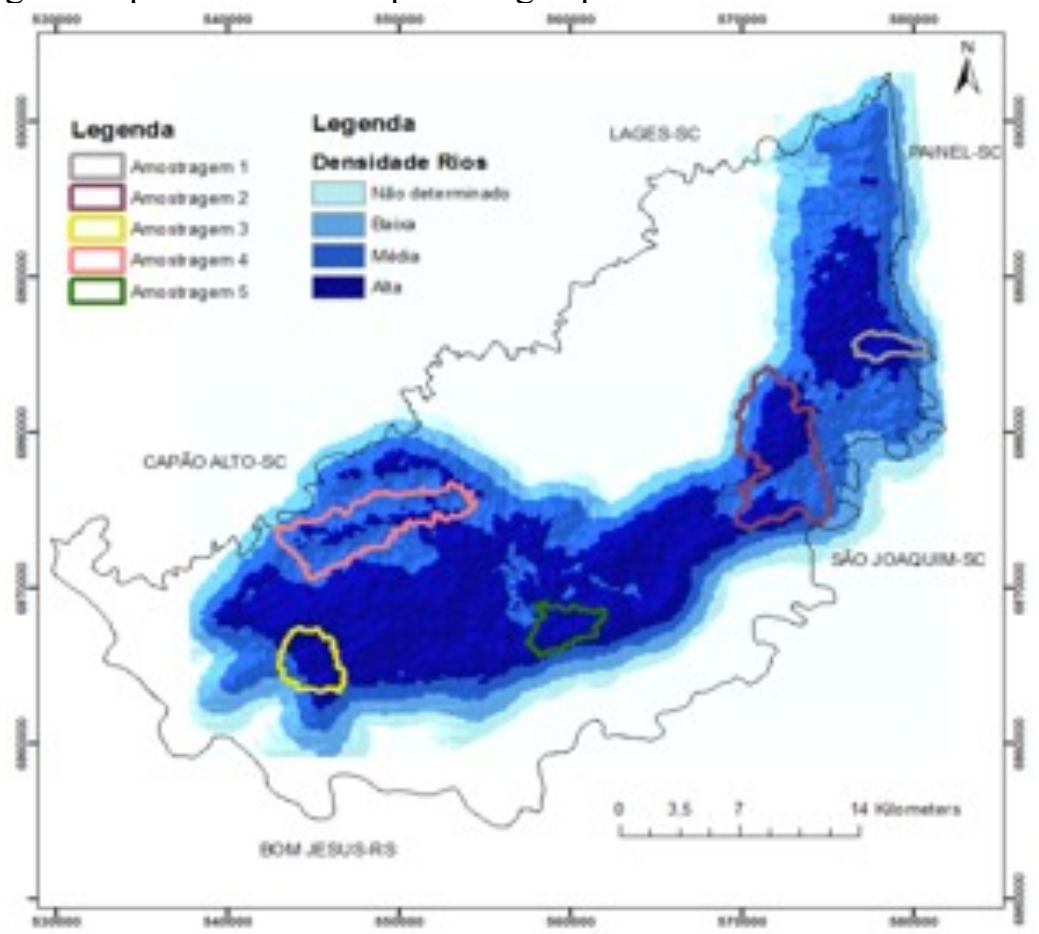

Figura 5: Classificação de densidades de corpos de água na área alvo de estudo e respectivas áreas de amostragem. 
POLESE, C. et al. Análise da hidrografia da Coxilha Rica, Sul do município...

As cinco áreas de amostragem foram selecionadas a fim de possibilitar uma melhor análise relacionada à importância da região como fornecedora de água através da quantificação dos corpos de água e das nascentes em cada área amostrada.

A área de amostragem 1 apresentou, em um território de 4,76 $\mathrm{Km}^{2}, 93$ corpos de água, somando 23,21 Km de extensão e 68 nascentes (Figura 6), sendo que mais de dois terços da área enquadrou-se nas classes de média e alta densidade de corpos de água. De acordo com os dados, tem-se que para cada $\mathrm{km}^{2}$ da área amostrada, existem aproximadamente 20 corpos de água e 15 nascentes.

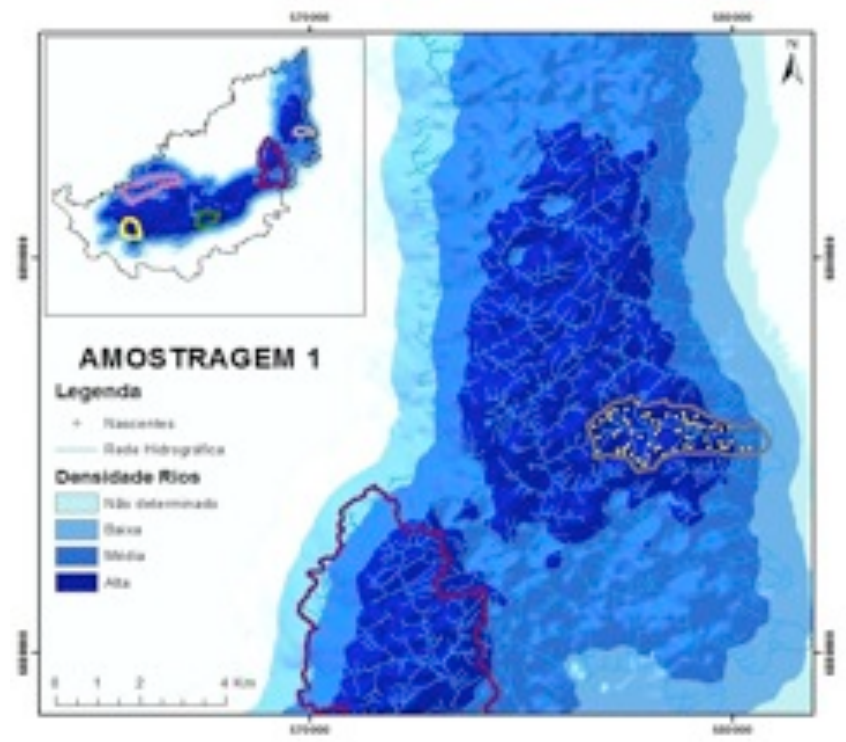

Figura 6: Classificação de densidades de corpos de água e quantificação de nascentes, com destaque para área de amostragem 1.

A área de amostragem 2 apresentou em um território de $36,15 \mathrm{Km}^{2}, 458$ corpos de água, somando $156,81 \mathrm{~km}$ de extensão e 338 nascentes (Figura 7). Observou-se que a área de amostragem ficou dividida entre as classes de média e de alta densidade de 
POLESE, C. et al. Análise da hidrografia da Coxilha Rica, Sul do município...

corpos de água, contando apenas com uma pequena faixa ao norte enquadrada em baixa densidade. De acordo com os dados, tem-se que para cada $\mathrm{km}^{2}$ da área amostrada, existem 13 corpos de água e 9 nascentes.

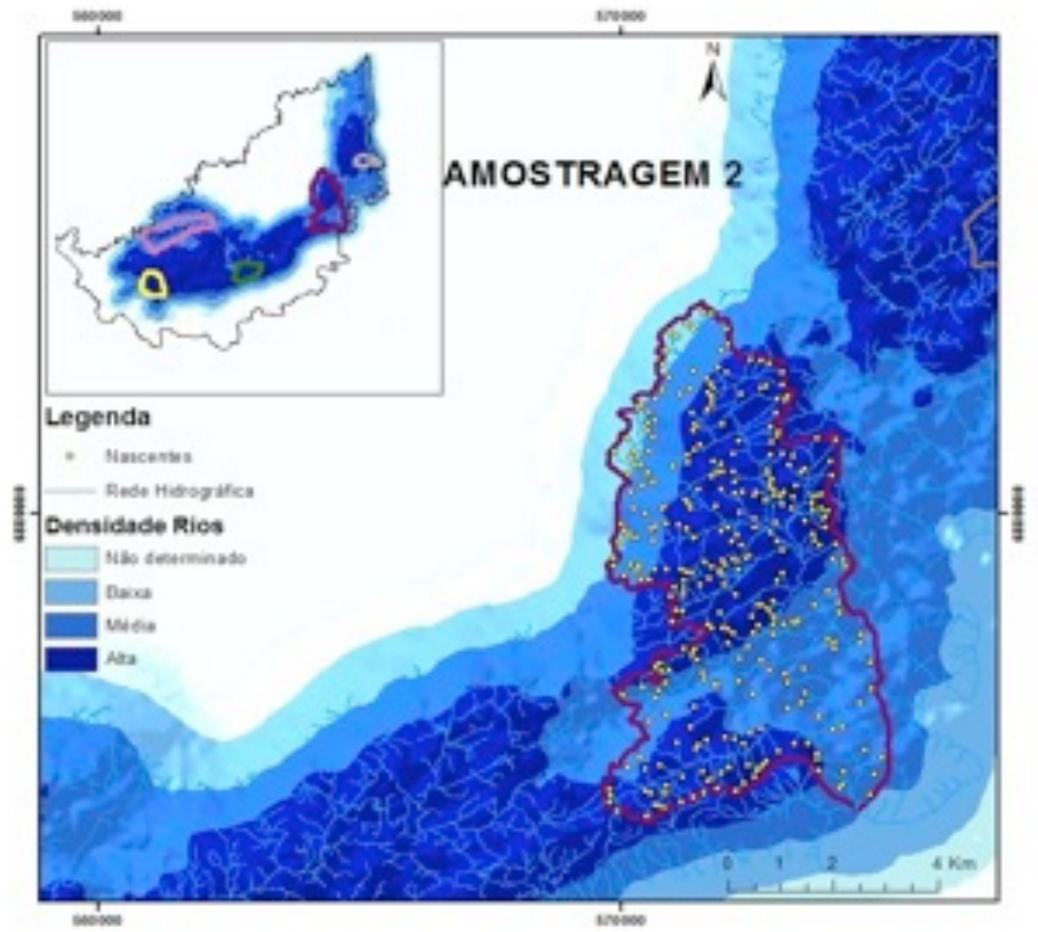

Figura 7: Classificação de densidades de corpos de água e quantificação de nascentes, com destaque para área de amostragem 2 .

A área de amostragem 3 apresentou em um território de $11,33 \mathrm{Km}^{2}, 141$ corpos de água, somando 53,11 Km de extensão e 99 nascentes (Figura 8), classificada cerca de três quartos da área na classe de densidade de corpos de água alta, e apenas um quarto 
POLESE, C. et al. Análise da hidrografia da Coxilha Rica, Sul do município...

da área na classe média de densidade. De acordo com os dados, tem-se que para cada $\mathrm{km}^{2}$ da área amostrada, existem 12 corpos de água e 9 nascentes.

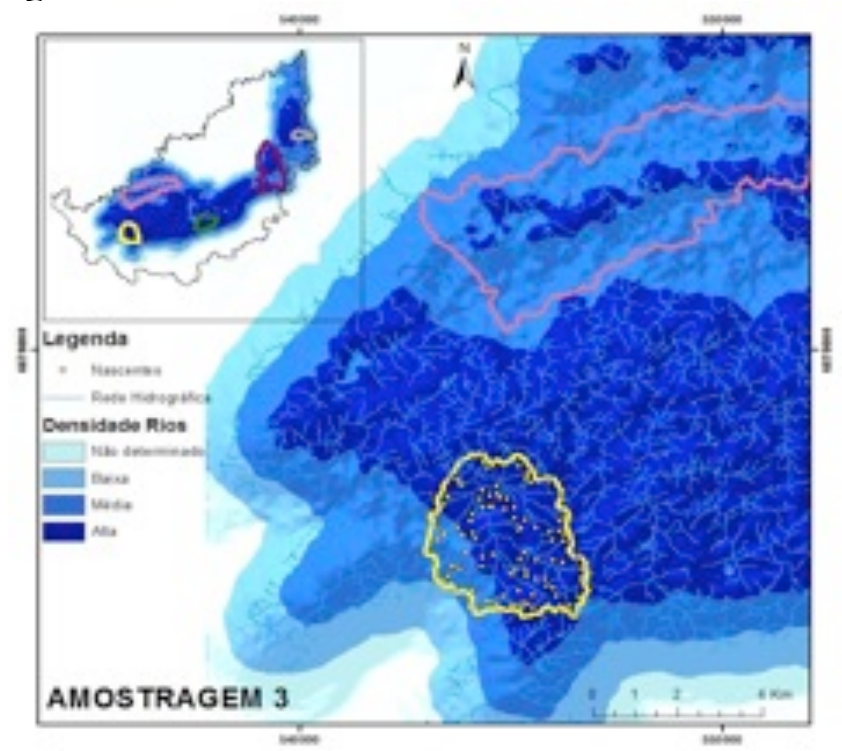

Figura 8: Classificação de densidades de corpos de água e quantificação de nascentes, com destaque para área de amostragem 3.

A área de amostragem 4 apresentou em um território de 28,86 Km², 269 corpos de água, somando 114,22 Km de extensão e 187 nascentes (Figura 9), sendo que grande parte da área se enquadrou na classe de média densidade de corpos de água e somente a parte central da área de amostragem na classe de alta densidade. De acordo com os dados, tem-se que para cada $\mathrm{km}^{2} \mathrm{da}$ área amostrada, existem 9 corpos de água e 6 nascentes. 
POLESE, C. et al. Análise da hidrografia da Coxilha Rica, Sul do município...

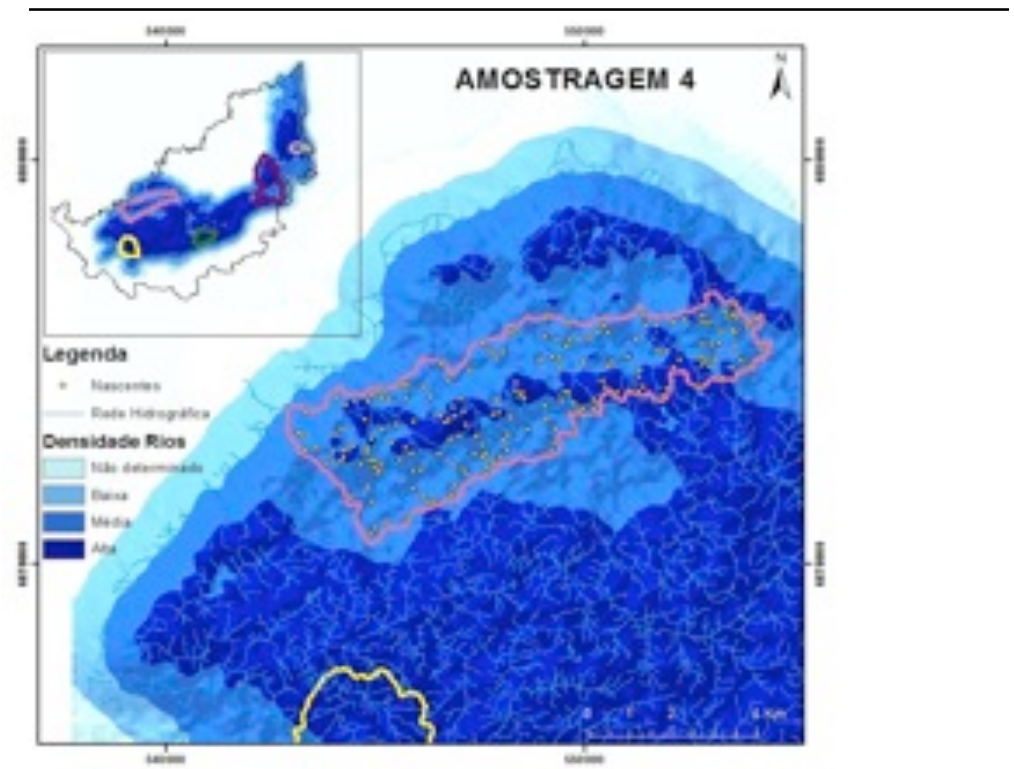

Figura 9: Classificação de densidades de corpos de água e quantificação de nascentes, com destaque para área de amostragem 4.

A área de amostragem 5 apresentou em um território de 8,79 $\mathrm{Km}^{2}, 89$ corpos de água, somando $42,14 \mathrm{Km}$ de extensão e 74 nascentes (Figura 10), tendo se enquadrado inteiramente na classe de densidade de corpos de água alta. De acordo com os dados, temse que para cada $\mathrm{km}^{2}$ da área amostrada, existem 10 corpos de água e 8 nascentes. 
POLESE, C. et al. Análise da hidrografia da Coxilha Rica, Sul do município...

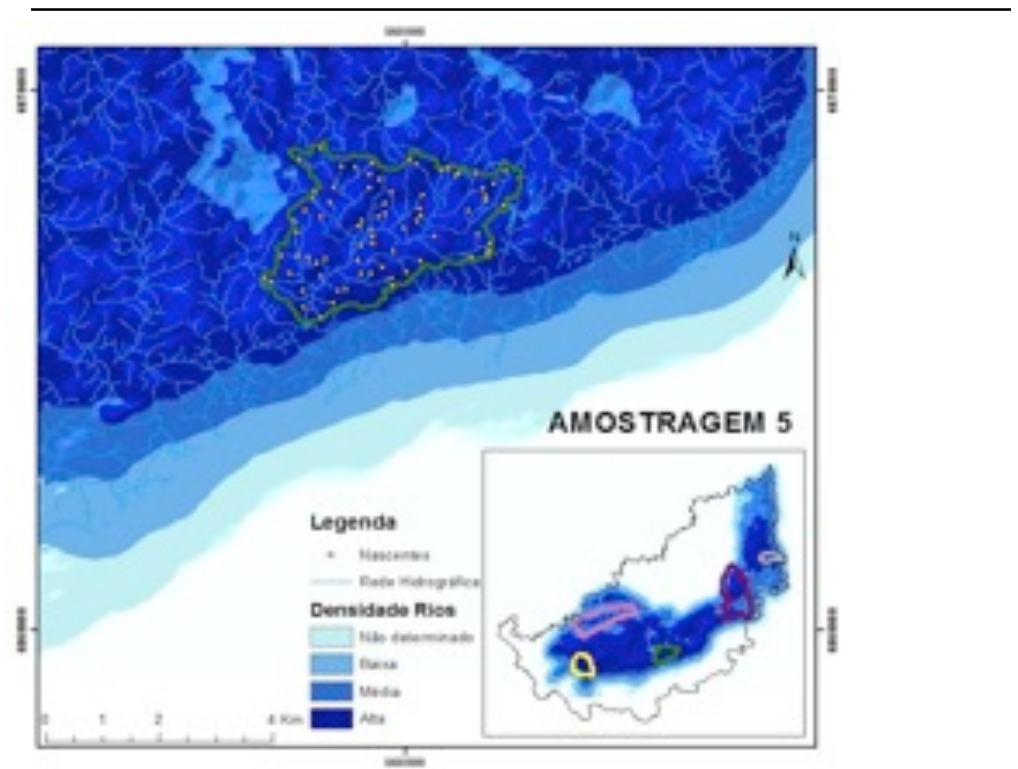

Figura 10: Classificação de densidades de corpos de água e quantificação de nascentes, com destaque para área de amostragem 5 .

Observa-se, portanto que nas cinco áreas de amostragem, há mais corpos de água do que nascentes. Esse fato pode ser explicado se for considerado que o corpo de água que corre da nascente, ao juntar-se com outro corpo de água, acaba formando, em alguns casos, um terceiro corpo de água, que não necessariamente tem origem em uma nascente.

Ainda, foram calculadas ás áreas de preservação permanente ao longo dos corpos de água e das nascentes, baseado na metragem estabelecida na legislação, para as 5 áreas de amostragem e de acordo com os resultados encontrados, as áreas de preservação permanente corresponderam em média a $28 \%$ do território da área alvo. 
POLESE, C. et al. Análise da hidrografia da Coxilha Rica, Sul do município...

Os dados encontrados como resultados demonstram a alta quantidade de corpos de água e de nascentes em todas as áreas de amostragem. Baseado nos resultados das áreas de amostragem fezse uma estimativa do total de nascentes para toda a área alvo, resultando em aproximadamente 4.970 nascentes. Portanto, podese afirmar que assim como as áreas amostradas, o território todo da Coxilha Rica, com seus $1.136,5 \mathrm{Km}^{2}$, é detentor de uma hidrografia considerável, a qual deve ser analisada como fornecedora de água de qualidade para a bacia hidrográfica a que pertence.

Essa qualidade encontrada na água presente no território da Coxilha Rica pode ser explicada pelo uso e ocupação do solo. De acordo com a classificação feita a partir do levantamento aerofotogramétrico da área, na escala 1:10.000, a Coxilha Rica conta com 752,94 $\mathrm{Km}^{2}$ de campos naturais ou pastagens. Estes, em grande parte são explorados pela atividade de pecuária extensiva, com baixa lotação de animais, produzindo dessa forma um baixo impacto aos corpos de água.

O uso e a ocupação do solo exercem influência no escoamento superficial e aporte de sedimentos nos leitos dos cursos d'água, podendo alterar a qualidade e a disponibilidade da água. Donadio et al. (2005), avaliando a influência da vegetação natural remanescente e de atividades agrícolas na qualidade da água de quatro nascentes, concluíram que os diferentes usos do solo influenciam na qualidade da água das sub-bacias, uma vez que a cobertura do solo representa um obstáculo mecânico ao livre escoamento superficial da água, ocasionando diminuição da velocidade e da capacidade de desagregação e transporte de sedimentos (Silva et. al., 2005).

\section{Considerações finais}

A água doce é um recurso natural finito, cuja qualidade vem decaindo devido a diversos fatores, tendo como principais, a poluição provocada pelo ser humano, o uso inadequado do solo e a ausência de políticas públicas voltadas para a sua preservação. 
POLESE, C. et al. Análise da hidrografia da Coxilha Rica, Sul do município...

A região da Coxilha Rica é detentora de grande quantidade de corpos de água e nascentes, fornecendo água de qualidade para a bacia hidrográfica a qual pertence. Para que seja possível a manutenção da qualidade da água, é de extrema necessidade o cumprimento à legislação ambiental, principalmente no que diz respeito aos padrões e limites para garantia da proteção do meio ambiente. As áreas de preservação permanente, como a mata ciliar, são igualmente importantes para a qualidade da água, pois estabelece uma faixa de vegetação junto aos corpos de água, servindo como filtro dos poluentes transportados pelo deflúvio.

A Coxilha Riba alberga quantitativamente por $\mathrm{Km}^{2}$ um numero de nascentes e corpos de água capaz de despertar o apetite do agronegócio, nestes tempos de alta procura por este extraordinário bem que é a água.

\section{Referências bibliográficas}

Detzel - Detzel Consultores Associados S/S. Plano Estratégico de Desenvolvimento para a Coxilha Rica - Fase I: Diagnóstico Socioeconômico e Ambiental. Florianópolis: 2010.

ENGEVIX. Estudo de Impacto Ambiental para Aproveitamento Hidrelétrico Pai Querê. Consórcio Empresarial Pai-Quêre. 2003.

EPE - Empresa de Pesquisa Energética. Avaliação Ambiental Integrada (AII) dos Aproveitamentos Hidrelétricos da Bacia Hidrográfica do Rio Uruguai. Consórcio Themag - Andrade \& Canellas - Bourscheid. 2006.

ETS - Energia, Transporte e Saneamento Ltda. Relatório Ambiental Simplificado da Bacia Hidrográfica do Rio Lava Tudo. Florianópolis: 2005. 
POLESE, C. et al. Análise da hidrografia da Coxilha Rica, Sul do município...

IBGE - Instituto Brasileiro de Geografia e Estatística. Mapa de clima do Brasil. Escala 1:5.000.000. Diretoria de Geociências, Rio de Janeiro: 2002.

Machado, R. E.; Vettorazi, C. A.; Xavier, A. C. Simulação de cenários alternativos de uso da terra em uma microbacia utilizando técnicas de modelagem e geoprocessamento. Revista Brasileira de Ciência do Solo, v.27, p.727-733, 2003.

NIMER, E. Climatologia do Brasil. 2a ed. IBGE. Rio de Janeiro: 1989.

RTK Engenharia Ltda. Estudo Ambiental Integrado da Bacia do Rio Pelotinhas. Florianópolis: 2005.

Silva, D. D.; Pruski, F. F.; Schaefer, C. E. G. R.; Amorim, R. S. S.; Paiva, K. W. N. Efeito da cobertura nas perdas de solo em um Argissolo Vermelho-Amarelo utilizando simulador de chuva. Engenharia Agrícola, v.25, n.2, p.409-419, 2005

Recebido em janeiro de 2014 Aceito em março de 2015 